\title{
ACCESO A LA JUSTICIA EN LAS RELACIONES PRIVADAS INTERNACIONALES: INTERESES EN JUEGO*
}

\section{ACESSO À JUSTICA NAS RELACÕES INTERNACIONAIS PRIVADAS: INTERESSES EM JOGO}

María Mercedes Albornoz $z^{* *}$

Resumen: En el acceso a lajusticia en las relaciones privadas internacionales gravitan el interés de las personas físicas o morales involucradas y el del Estado cuyos jueces podrían intervenir para solucionar una controversia concreta. El interés de las personas consiste en ejercer el derecho de acceso a la justicia que les corresponde, como medio para satisfacer una pretensión sustantiva. Aquel del Estado, por su parte, radica en limitar el número de casos en los cuales sus tribunales asumen jurisdicción para resolver el fondo de la disputa. Pero el Estado también está interesado en que las personas accedan a la justicia. Este artículo destaca la importancia del acceso a la justicia en las relaciones privadas internacionales y analiza cómo se puede buscar un equilibrio entre dos necesidades diferentes. Por un lado, la de garantizar el acceso de los particulares a la justicia. Por el otro, la de restringir el alcance de jurisdicción internacional directa. Se afirma que ello puede lograrse utilizando con suma precaución ciertas herramientas del derecho internacional privado.

Resumo: No acesso à justiça nas relações privadas internacionais gravitam o interesse das pessoas físicas ou morais envolvidas e do Estado cujos juízes poderiam intervir para resolver uma controvérsia específica. O interesse das pessoas é exercer o direito de acesso à justiça que merecem, como um meio de satisfazer uma reivindicação substancial. $O$ do Estado, por sua parte, está em limitar o número de casos nos quais os tribunais assumem jurisdição para resolver o mérito da disputa. Mas também o Estado está interessado em que as pessoas acedam à justiça. Este artigo destaca a

\footnotetext{
* Parte de este trabajo fue publicado en el artículo ALBORNOZ, María Mercedes. "Acceso a la justicia en las relaciones privadas internacionales: intereses en juego". Juez. Cuadernos de Investigación. 2016, $\mathrm{n}^{\circ}$ 4, p. 11-35.

** Centro de Investigación y Docencia Económicas - CIDE, México.

E-mail: mercedes.albornoz@cide.edu

Recibido: 4/08/2016. Aceptado: 23/01/2017.
} 
importância do acesso à justiça nas relações privadas internacionais e discute como se pode pesquisar um equilibrio entre duas necessidades diferentes. Por um lado, de garantir o acesso das pessoas à justiça. Por outro lado, restringir o alcance da jurisdição internacional direta. Afirmase que isto pode ser conseguido usando com muita precaução certas ferramentas do direito internacional privado.

Palabras clave: Acceso a la justicia, Jurisdicción internacional, Relaciones privadas internacionales, Derecho internacional privado Palavras-chave: Acesso à justiça, Jurisdição internacional, Relações privadas internacionais, Direito internacional privado

\section{INTRODUCCIÓN}

A lo largo de la vida de las relaciones jurídicas entre sujetos particulares, diversas circunstancias pueden dar lugar al surgimiento de controversias. Cuando las personas físicas o morales que son partes en el conflicto no logran solucionarlo mediante una negociación directa, es habitual que consideren la posibilidad de dar intervención a un órgano jurisdiccional del Estado para que éste resuelva el litigio e incluso pueda ejecutar su decisión coactivamente, en caso de ser necesario. El acceso efectivo a la justicia, o derecho a la efectividad de la tutela jurisdiccional, es considerado "consustancial a todo Estado". Supone que el particular pueda acudir a un tribunal y que en el transcurso de todo el proceso -desde el inicio hasta la ejecución de la sentencia inclusive- ciertas garantías mínimas sean respetadas, de manera que la persona pueda esclarecer su situación jurídica y ver satisfecha su pretensión sustantiva. Este derecho asiste tanto a la parte actora como a la parte demandada.

En el orden interno de los países latinoamericanos, distintos factores $^{2}$ entre los cuales sobresale la pobreza ${ }^{3}$, constituyen barreras

1 GONZÁLEZ PÉREZ, Jesús. El derecho a la tutela jurisdiccional. $3^{\text {a }}$ ed. Madrid: Civitas Ediciones, 2001, p. 25.

2 Piénsese por ejemplo en la burocratización de las instituciones impartidoras de justicia, o en cuestiones relativas a características intrínsecas de las partes, tales como género, etnia, lengua, educación, entorno cultural. Véase el estudio Obstáculos para el acceso a la justicia en las Américas, presentado por Due Process of Law y el Instituto de Defensa Legal ante el Comité Jurídico Interamericano en agosto de 2009, p. 6. [último acceso: 20/09/2015] <http://dplf.org/sites/default/ files/obstaculos_para_el_acceso_a_la_justicia_en_las_americas_version_final.pdf $>$

3 En efecto, "la cuestión económica es un factor determinante a la hora de que una persona decida llevar sus necesidades de definición de situaciones jurídicas a las instancias de justicia (...) se convierte o puede convertirse en un obstáculo insalvable”. THOMPSON, José. "Comparación de resultados". En THOMPSON, José (ed.). Acceso a la justicia y equidad. Estudio en siete países de América Latina. San José: Banco Interamericano de Desarrollo, Instituto Interamericano de Derechos Humanos, 2000, p. 415. Otro elemento que dificulta aún más a la población en situación de desventaja económica acceder a la justicia y confiar en el sistema es la "distancia" entre los jueces y la población. GARGARELLA, Roberto. Too far Removed from the People. Access to justice for the poor: the case of Latin America, 2002. [último 
que dificultan o impiden el acceso de los ciudadanos a la justicia. Este fenómeno no es exclusivo del ámbito penal -donde se da con particular crudeza $^{4}$ - sino que existe desde hace tiempo en otras esferas, como la de la justicia civil y mercantil ${ }^{5}$.

Ahora bien, en la época actual resulta cada vez más frecuente que las relaciones jurídicas entre particulares presenten puntos de contacto con los ordenamientos jurídicos de dos o más Estados. En otras palabras, que sean relaciones pluriconectadas o transfronterizas. Cuando surge una controversia en una relación privada internacional, la cuestión del acceso a la justicia se vuelve más compleja que en el orden doméstico aún, ante la posibilidad de demandar o ser demandado en el extranjero. A las múltiples dificultades inherentes a la participación en un proceso en una jurisdicción extraña -costo, distancia, probable utilización de un idioma extranjero, falta de familiaridad con el foro y su sistema jurídicose suma la incertidumbre en cuanto a las posibilidades reales de obtener el reconocimiento y la eventual ejecución de la sentencia en un país distinto de aquél al que pertenece el juez investido de jurisdicción directa.

Al existir un conflicto en el marco deuna relación privadainternacional entran en escena el interés de los particulares de acceder a la justicia como un medio para satisfacer su pretensión de fondo y el interés divergente del Estado de limitar la cantidad de causas radicadas ante sus tribunales. Dicha divergencia resulta atenuada por la obligación estatal de garantizar el acceso a la justicia; no obstante, no desaparece. Por consiguiente, se considera relevante analizar cómo la utilización de herramientas de derecho internacional privado puede contribuir en la búsqueda de un equilibrio entre los diversos intereses que aparecen en escena. Para ello, previamente se abordarán los intereses en juego, identificando la convergencia y la divergencia entre ellos, en el contexto de conflictos surgidos en ocasión relaciones privadas pluriconectadas. Finalmente, de cara al futuro, se propone seguir algunas líneas de acción a efectos de facilitar el acceso a la justicia en las relaciones privadas internacionales.

Antes de comenzar con el análisis de los intereses involucrados, cabe formular algunas aclaraciones con respecto a los mecanismos alternativos de solución de controversias, en los cuales interviene un

acceso: 20/09/2015]. Disponible en: <http://www.ucl.ac.uk/dpu-projects/drivers_urb_change/ urb_society/pdf_violence_rights/gargarella_removed_from_people.pdf $>$

4 "Se trata de una desigualdad odiosa, pues ataca el terreno de las libertades fundamentales en todos los momentos decisivos de la intervención penal: desigualdad en la exposición a la intervención punitiva, desigualdad de derechos en el proceso, desigualdad de tratamiento en la ejecución penal". FERRAJOLI, Luigi. "La desigualdad ante la justicia penal y la garantía de la defensa pública". En MINISTERIO PÚBLICO DE LA DEFENSA, ASOCIACIÓN INTERAMERICANA DE DEFENSORÍAS PÚBLICAS. Defensa pública: garantía de acceso a la justicia. Buenos Aires: Editorial La Ley, 2008, p. 77.

5 La desigualdad generada por la pobreza "es un fenómeno absolutamente evidente en lo que se refiere a la justicia civil, cuyos tiempos larguísimos y costos excesivos se resuelven, para las personas más pobres, en una denegación de justicia”. Ídem. 
tercero neutral que no es un órgano del Estado. Estos mecanismos quedan comprendidos en una noción extensiva de acceso a la justicia ${ }^{6}$. Tanto dichos medios en general como el arbitraje comercial internacional en particular, en principio quedarán excluidos del desarrollo de este trabajo. El arbitraje como método alternativo de solución de controversias de carácter privado se emplea frecuentemente en el mundo y contribuye a dar respuesta a la necesidad de acceso a la justicia de buena parte de los operadores del comercio internacional. Sobre este punto es preciso hacer dos observaciones. En primer lugar, el interés del Estado no se manifiesta de la misma manera en la vía jurisdiccional y en la vía arbitral -al menos mientras el arbitraje no requiera la intervención de los jueces-. En la esfera judicial el Estado establece directamente cuándo son o no son competentes sus tribunales, en tanto que con respecto al arbitraje comercial internacional, una vez que lo permite, puede decirse que de modo indirecto lo incentiva en la medida en la que exige más requisitos para la competencia internacional de sus jueces ${ }^{7}$. En segundo lugar, en América Latina todavía muchas controversias derivadas del comercio transfronterizo se ventilan ante los tribunales estatales. Esta realidad se verifica especialmente en regiones como la nuestra, puesto que a pesar de los esfuerzos emprendidos en décadas recientes, el desarrollo de la "cultura del arbitraje" no ha alcanzado aún un grado de maduración equivalente al obtenido en otras plazas ${ }^{8}$ y que el arbitraje comercial internacional comporta un costo elevado para las partes ${ }^{9}$. En

6 En este sentido, Mauricio Padrón Innamorato aclara que "la justicia no debe entenderse de manera exclusiva, sólo como justicia de Estado". El autor señala la importancia de no desconocer las situaciones de exclusión social "a las que se ven expuestos grandes sectores de la población (...) [y su] relación recíproca con la justicia y el acceso a ésta". "Acceso a la justicia, vulnerabilidad y exclusión: aproximación a las relaciones dimensionales subyacentes", sin derechos. Exclusión y discriminación en el México actual. México: Instituto de Investigaciones Jurídicas, 2014, p. 70. [último acceso: 20.09.2015]. Disponible en: <http://biblio.juridicas. unam.mx/libros/8/3541/6.pdf $>$. Sobre el acceso a la justicia a través de la mediación, véase en la misma obra colectiva la contribución de GONZÁLEZ MARTÍN, Nuria. Un acercamiento al acceso a la justicia a través de la mediación como medio alterno de solución de conflictos, p. 103-139 [último acceso: 20.09.2015]. Disponible en: <http://biblio.juridicas.unam.mx/ libros/8/3541/7.pdf>

7 Diego P. Fernández Arroyo señala que los sistemas jurídicos que incluyen requisitos de proximidad para que sus tribunales sean competentes desempeñan un importante papel de promoción del arbitraje. Si las partes encuentran allí obstáculos objetivos, generalmente podrán recurrir al arbitraje. El autor se pregunta si no es ésa la verdadera razón por la cual se mantiene la exigencia de proximidad. "The limits to the parties' free choice of jurisdiction - formal and territorial requirements for the efficacy of choice-of-court agreements". En GRIGERA NAÓN, Horacio A. y AFFAKI, Bachir Georges (eds.). Jurisdictional Choices in Times of Trouble, Dossiers of the ICC Institute of World Business Law, Volume 12, capítulo 5, Kluwer Law International, International Chamber of Commerce (ICC), 2015, p. 78.

8 Véase KLEINHEISTERKAMP, Jan. International Commercial Arbitration in Latin America. Nueva York: Oceana Publications, 2005, p. 1.

9 Mariana Hernández Crespo distingue tres niveles de justicia en la región, a saber: "arbitraje privado, para quienes pueden pagar un árbitro; el sistema judicial, para quienes pueden pagar un abogado; y centros de mediación para quienes no pueden pagar ni lo uno ni lo otro". "Securing Investment: Innovative Business Strategies for Conflict Management in Latin 
virtud de estos dos puntos, el presente artículo se concentrará en los intereses en juego en el acceso a la justicia en el supuesto de que las partes de una controversia privada internacional acuden a un órgano jurisdiccional estatal.

\section{LOS INTERESES EN JUEGO: CONVERGENCIA Y DIVERGENCIA}

Cuando surgen diferendos entre las partes de relaciones jurídicas privadas transfronterizas de carácter civil o mercantil, entran en juego diversos intereses de los particulares y los del Estado en torno a la posibilidad de que los primeros requieran los servicios del segundo para solucionar controversias. Esta sección tratará primeramente la convergencia de intereses en el acceso a la justicia, que será examinado como derecho humano del justiciable y como obligación del Estado, para abordar luego la divergencia de intereses entre la limitación de la jurisdicción estatal y el acceso a la justicia.

\subsection{Convergencia de intereses}

El acceso a la justicia como derecho humano del justiciable y como obligación del Estado

Los intereses de los particulares y del Estado hallan en el acceso a la justicia un punto de convergencia. En este sentido, el acceso a la justicia cuenta con dos facetas que se complementan. Cual caras de una misma moneda, no podría existir una sin la otra. Así, al derecho de las personas físicas y morales de obtener una respuesta jurisdiccional ante un conflicto, corresponde la obligación del Estado de garantizarles un acceso efectivo a la justicia, mediante la actividad de sus órganos jurisdiccionales.

En el orden internacional, la noción de acceso a la justicia se va configurando de manera dinámica ${ }^{10}$, tomando elementos de un amplio abanico de fuentes normativas tales como tratados internacionales, declaraciones, sentencias, opiniones y doctrina. Ese acceso es establecido como un derecho para los particulares y, a la vez, como una obligación para los Estados.

Aunque su consagración en instrumentos internacionales surgió

America". En INGEN-HOUSZ, Arnold (ed.). ADR in Business: Practice and Issues across Countries and Cultures II, capítulo 22, Kluwer Law International, 2010, p. 460.

$10 \mathrm{El}$ derecho de acceso a la justicia "se encuentra sujeto a un proceso de evolución que no ha concluido". ORTIZ AHLF, Loretta, "El derecho de acceso a la justicia". En BECERRA RAMÍREZ, Manuel et al. (ed.). Obra en homenaje a Rodolfo Cruz Miramontes. México: Instituto de Investigaciones Jurídicas, 2008, t. II, p. 408. [último acceso: 20/09/2015]. Disponible en: <http://biblio.juridicas.unam.mx/libros/6/2547/20.pdf> 
en reacción a la existencia de crímenes de lesa humanidad ${ }^{11}$ que permanecían impunes, tuvo lugar mediante normas muy generales. La Declaración Universal de Derechos Humanos adoptada en 1948 dispone que "Toda persona tiene derecho a un recurso efectivo, ante los tribunales nacionales competentes, que la ampare contra actos que violen sus derechos fundamentales reconocidos por la constitución o por la ley" (artículo 8). Con el correr de los años, el acceso a la justicia ha sido delineado de manera más detallada por otros instrumentos. Tal es el caso del Pacto internacional de derechos civiles y políticos de 1966, cuyo artículo 14 reza: “Todas las personas son iguales ante los tribunales y cortes de justicia. Toda persona tendrá derecho a ser oída públicamente y con las debidas garantías por un tribunal competente, independiente e imparcial, establecido por la ley, en la sustanciación de cualquier acusación de carácter penal formulada contra ella o para la determinación de sus derechos u obligaciones de carácter civil". Instaura, además, una serie de garantías para el acusado en un proceso penal. A nivel regional, la Convención Americana sobre Derechos Humanos de 1969 regula el derecho a la libertad personal (artículo 7) e instituye garantías judiciales (artículo 8). El artículo 8 de la convención dispone: "Toda persona tiene derecho a ser oída, con las debidas garantías y dentro de un plazo razonable, por un juez o tribunal competente, independiente e imparcial, establecido con anterioridad por la ley, en la sustanciación de cualquier acusación penal formulada contra ella, o para la determinación de sus derechos y obligaciones de orden civil, laboral, fiscal o de cualquier otro carácter" y determina garantías para el inculpado en un proceso de carácter penal.

Una concepción moderna ${ }^{12}$ de la noción de acceso a la justicia, característica del siglo XX, aunque continúa evolucionando en pleno siglo XXI, parte del reconocimiento de los derechos y las obligaciones sociales de gobiernos, comunidades, asociaciones, individuos y de la preocupación de hacerlos accesibles para todos ${ }^{13}$. Por tal motivo, se requiere que el Estado desempeñe un papel activo a fin de asegurar que la población disfrute esos derechos sociales básicos. Entre ellos se destaca el acceso a la justicia como un mecanismo para la aplicación efectiva de los demás ${ }^{14}$. Por consiguiente, el acceso a la justicia es considerado un derecho humano ${ }^{15}$ del justiciable.

11 Ibíd., p. 408-409.

12 Por oposición a la que dominó durante finales del siglo XVIII y el siglo XIX, que veía el acceso a la justicia como un derecho meramente formal a litigar, a hacer valer los derechos propios y defenderlos, lo que llevaba a que el Estado adoptara una actitud pasiva en cuanto a los problemas en la implementación práctica del acceso. CAPELLETTI, Mauro y GARTH, Bryant. El acceso a la justicia. La tendencia en el movimiento mundial para hacer efectivos los derechos. Trad. de Mónica Miranda. México: Fondo de Cultura Económica, 1996, p. 11.

13 Ibíd., p. 12.

14 Ídem.

15 Mauro Capelletti y Bryant Garth entienden que puede vérselo como "el requisito más 
Ahora bien, el acceso a la justicia es un concepto complejo, uno de cuyos elementos centrales ${ }^{16}$ consiste en la idea de efectividad: el acceso carecería de sentido si no estuviese imbuido de aquélla. Esta circunstancia explica que en ocasiones se aluda a él como "acceso efectivo a la justicia". En realidad, la adición del adjetivo "efectivo" puede considerarse redundante ${ }^{17}$. De hecho, se estima que el "acceso a la justicia" en el ámbito judicial es equivalente a la "tutela judicial efectiva", aunque a veces se ubique a la segunda como un elemento de la primera ${ }^{18}$ o, a la inversa, a la primera como componente de la segunda ${ }^{19}$. Se puede entender que ambas nociones aluden a la misma realidad si se abraza una concepción amplia del acceso a la justicia, que no se agota al lograr ser parte en un proceso ante un juez que se declare competente, sino que llega hasta la obtención de una sentencia definitiva y hasta que se haya completado su ejecución.

Además de la extensión temporal mencionada en el párrafo precedente, la adopción de una concepción moderna y amplia del acceso a la justicia como derecho humano comporta al menos dos consecuencias más que también son relevantes para las relaciones privadas transfronterizas. Por un lado, el acceso a la justicia excede los supuestos de violaciones graves de los derechos humanos ${ }^{20}$ y el ámbito estrictamente penal, para expandir su radio de influencia y abarcar

\footnotetext{
básico -el "derecho humano" más fundamental- en un sistema legal igualitario moderno, que pretenda garantizar y no solamente proclamar los derechos de todos". Ibíd., p. 13. La Organización de los Estados Americanos se refiere al acceso a la justicia como un "derecho humano fundamental" que a la vez es "el medio que permite restablecer el ejercicio de aquellos derechos que hubiesen sido desconocidos o vulnerados”. AG/RES 2801 (XLIII-O/13), 5 de junio de 2013. [último acceso: 20/09/2015]. Disponible en: <http://www.oas.org/es/sla/ddi/ docs/AG-RES_2801_XLIII-O-13.pdf>

16 Otro elemento importante del acceso a la justicia, sobre el que no nos detendremos aquí, es el debido proceso. Para un estudio reciente de la configuración de este principio en América Latina, véase CABALLERO JUÁREZ, José Antonio. El debido proceso. Una aproximación desde la jurisprudencia latinoamericana. México: Suprema Corte de Justicia de la Nación, Oficina en México del Alto Comisionado de las Naciones Unidas para los Derechos Humanos, 2014.

17 Javier L. OCHOA MUÑOZ lo considera un "agregado retórico". "Algunas consideraciones sobre el acceso internacional a la justicia. Hacia un derecho internacional privado al servicio de la justicia”. En MORENO RODRÍGUEZ, José Antonio y MARQUES, Claudia Lima (ed.). Los servicios en el derecho internacional privado. Jornadas de la ASADIP 2014. Porto Alegre, 30-31 de octubre, Porto Alegre: ASADIP, UFRGS, 2014, p. 251.

18 Ídem.

19 Ésta podría ser la postura adoptada por un tribunal mexicano que, al referirse a la tutela judicial efectiva y el acceso a la jurisdicción, adoptó el siguiente criterio: “TUTELA JUDICIAL EFECTIVA. EL ACCESO A UN RECURSO EFECTIVO, SENCILLO Y RÁPIDO, ES CONSECUENCIA DE ESE DERECHO FUNDAMENTAL. ...el artículo 17 constitucional prevé el derecho fundamental a la tutela judicial efectiva, que supone, en primer término, el acceso a la jurisdicción, es decir, que el gobernado pueda ser parte en un proceso judicial y, en segundo, el derecho que tiene a obtener una sentencia sobre el fondo de la cuestión planteada y su cabal ejecución...”. Décima Época, Registro 2002096, Semanario Judicial de la Federación y su Gaceta, Libro XIII, Octubre de 2012, Tomo 4, Tesis: II.8º. (I Región) 1 K (10 a), p. 2864.

20 Piénsese por ejemplo en crímenes de lesa humanidad como el genocidio, la tortura o la desaparición forzada de personas.
} 
cualquier otra área ${ }^{21}$ en la cual surja una controversia. Por otro lado, el titular del derecho de acceso a la justicia puede ser tanto una persona física como una persona moral ${ }^{22}$. De esto se deriva que el acceso a la justicia, como derecho humano de los justiciables y como obligación de los Estados, les corresponde a quienes sean parte en conflictos surgidos en el marco relaciones privadas de carácter internacional, trátese de personas físicas o de personas morales, y desde el momento en el que surge el diferendo hasta aquél en el que se da cumplimiento a la sentencia.

El acceso a la justicia -concepto per se complejo- se vuelve más intrincadocuandosebuscagarantizar su existencia en el marco de relaciones iusprivatistas internacionales ${ }^{23}$. Para empezar, puede resultar difícil para las partes saber en qué país identificar un tribunal internacionalmente competente o anticipar dónde se podrá ser demandado. Asimismo, para el Estado no deja de ser un desafío la búsqueda de un equilibrio entre los derechos de las partes y la ausencia de discriminación en el tratamiento que se le confiere a cada una de ellas. Adicionalmente, suponiendo que una o ambas partes estén en condiciones de afrontar el costo de un probable litigio en el extranjero o que cuenten con algún tipo de apoyo del Estado para ello, puede aún persistir cierta incertidumbre en cuanto a la ejecutabilidad en un Estado de una sentencia dictada en otro. En cuanto a este último aspecto, cabe recordar que en principio se considera violatoria del derecho de acceso a la justicia toda decisión infundada de no reconocer una sentencia dictada en el extranjero ${ }^{24}$.

En este escenario, ante la ausencia de una instancia supranacional facultada para resolver conflictos de jurisdicción o competencia entre

21 Por ejemplo, contratos internacionales, responsabilidad extracontractual. Esta última puede violar derechos humanos, como ha sucedido en el célebre caso Kiobel. Corte Suprema de los Estados Unidos, Kiobel, individually and on behalf of her late husband Kiobel et al. v. Royal Dutch Petroleum Co. et al., 17 de abril de 2013, No 10-1491. Disponible en: <https:// supreme.justia.com/cases/federal/us/569/10-1491/> [último acceso: 20.09.2015].

22 El pleno de la Suprema Corte de Justicia mexicana adoptó recientemente una jurisprudencia constitucional que resulta aplicable al derecho de acceso a la justicia de las personas morales. "PRINCIPIO DE INTERPRETACIÓN MÁS FAVORABLE A LA PERSONA. ES APLICABLE RESPECTO DE LAS NORMAS RELATIVAS A LOS DERECHOS HUMANOS DE LOS QUE SEAN TITULARES LAS PERSONAS MORALES. El artículo $1^{\circ}$ de la Constitución Política de los Estados Unidos Mexicanos, al disponer que en los Estados Unidos Mexicanos todas las personas gozarán de los derechos humanos reconocidos en dicha Constitución y en los tratados internacionales de los que el Estado Mexicano sea parte, así como de las garantías para su protección, no prevé distinción alguna, por lo que debe interpretarse en el sentido de que comprende tanto a las personas físicas, como a las morales, las que gozarán de aquellos derechos en la medida en que resulten conformes con su naturaleza y fines...". Décima Epoca, Registro 2008584, Semanario Judicial de la Federación y su Gaceta, Libro 16, Marzo de 2015, Tomo 1, Tesis: P./J. 1/2015 (10 $)$, p. 117.

23 La precisión del contenido y el alcance del acceso a la justicia en situaciones internacionales no es una cuestión simple ni de obvia resolución. FERNANDEZ ARROYO, Diego P. "La tendance à la limitation de la compétence judiciaire à l'épreuve du droit d'accès à la justice", en D’AVOUT, Louis et al. (ed.). Mélanges en l'honneur du Professeur Bernard Audit. Les relations privées internationales. Paris: LGDJ, Lextenso éditions, 2014, p. 299.

24 Ídem. 
tribunales de distintos países y tomando en cuenta que las diversas jurisdicciones estatales concurrentes se hallan en un plano de igualdad, adquiere una importancia clave la cooperación entre ellas. En efecto, "una concepción aislada del derecho de acceso internacional a la justicia, resulta totalmente contradictoria en sí misma, por lo que se hace necesaria una idea de coordinación y cooperación internacional, que suplante la de la plena separación recíproca de las soberanías"25.

\subsection{Divergencia de intereses: limitación de la jurisdicción estatal y acceso a la justicia}

Sería irrisorio y carente de sentido práctico pretender que los tribunales de un Estado contaran con jurisdicción directa para resolver cualquier controversia privada internacional que un demandante les planteara, sin la más mínima exigencia de proximidad entre el caso y el foro. El Estado en cuestión no tendría un motivo válido para poner en marcha su aparto jurisdiccional en tal situación y menos aún si se tiene en cuenta el costo ${ }^{26}$ que esto implicaría. Si muchos Estados adoptaran esta actitud expansionista extrema, se incrementarían exponencialmente los casos de litispendencia internacional. Adicionalmente, las posibilidades de obtener el reconocimiento y la ejecución de las sentencias dictadas en tales procesos serían completamente inciertas, lo que tornaría ineficaz todo el trabajo realizado.

Asimismo, aunque actualmente subsisten algunas manifestaciones de ánimo expansivo ${ }^{27}$, hay que tomar en cuenta que desde hace ya unas décadas un gran número de Estados tiende a restringir el ámbito de su competencia judicial internacional ${ }^{28}$. Ese interés del Estado en acotar la cantidad de causas radicadas ante sus órganos jurisdiccionales es divergente con respecto al interés de los particulares en acceder a la justicia. Son intereses que difieren entre sí y no parecen avanzar en la misma dirección: cuanto más se restringiera el alcance de la competencia internacional de un Estado, menor sería -en ese país- el acceso de las personas a la justicia. El hecho de que el Estado esté obligado a garantizar el acceso a la justicia contribuye a atenuar esa divergencia; sin embargo, no llega a borrarla.

25 OCHOA MUÑOZ. Op. cit.

26 Incluyendo recursos humanos, recursos materiales y, sobre todo, tiempo, que podrían ser dedicados a atender litigios vinculados con el foro cuya solución, por lo tanto, interesa al menos mediatamente al Estado.

27 Como una interpretación amplia de normas que establecen la competencia exclusiva de los tribunales de un Estado y como la subsistencia de ciertos foros exorbitantes. Sobre ambas cuestiones, véase FERNANDEZ ARROYO, Diego P. "Compétence exclusive et compétence exorbitante dans les relations privées internationales". Recueil des cours de l'Académie de Droit International. 2006, t. 323.

28 Acerca de esta tendencia y su evolución más reciente, véase FERNÁNDEZ ARROYO. Op. cit., p. 286 y ss. 
Como en la sección precedente se ha hecho referencia al acceso a la justicia en tanto derecho humano del justiciable y obligación del Estado, aquí se pondrá el foco en los motivos que conducen a la limitación de la competencia internacional del Estado y en cómo ésta se exterioriza.

El interés del Estado por restringir la cantidad de casos sometidos a su jurisdicción es un legítimo y atiende a una pluralidad de circunstancias. A dos de esas razones -consideradas de peso- se aludirá a continuación. Las mismas están presentes también cuando de diferencias domésticas se trata; pero confluyen en y refuerzan la contundencia de otra razón, característica de las controversias internacionales.

En primer lugar, hay una razón de tipo institucional. Los tribunales del Estado suelen estar sobrecargados y, tal como están organizados, muchas veces no dan abasto para tramitar en tiempo y forma la totalidad de las causas que reciben. Esa carencia de capacidad institucional ${ }^{29}$ ha originado la percepción de la administración de justicia como lenta e ineficaz e incluso ha impulsado la exploración de mecanismos alternativos de solución de controversias en países donde no se los utiliza de manera generalizada y frecuente ${ }^{30}$. En segundo lugar, y vinculada con la anterior, hay una razón de tipo económico. Poner un tribunal al servicio de las partes en una disputa, a fin de resolverla, tiene un costo para el Estado -e, indirectamente, también para los gobernados que pagan impuestos-. Una de las medidas a tomar para sacar mejor provecho de los recursos asignados al funcionamiento del tribunal consiste, precisamente, en procurar reducir o evitar el exceso de trabajo. Lo cierto es que esa sobrecarga guarda estrecha relación con el número de causas admitidas a trámite.

El tercer argumento que sustenta la restricción de la competencia internacional de los tribunales de un Estado es la razonabilidad. Aquí confluyen los dos motivos previamente mencionados y, a su vez, contribuyen a conferirle más fuerza al tercero. En efecto, no sería razonable que un Estado cuyos órganos de administración de justicia no dan abasto para atender los casos nacionales adoptara un criterio demasiado amplio en cuanto a la competencia de los mismos para resolver litigios internacionales entre particulares. Tampoco lo sería que el Estado invirtiera sus recursos económicos en costear el funcionamiento de sus tribunales a fin de que se diera solución a

29 Sobre éste y otros problemas del acceso a la justicia cotidiana en México, véase "Conclusiones y propuestas", en Centro de Investigación y Docencia Económicas, Informe de resultados de los Foros de Justicia Cotidiana, México, CIDE, abril 2015, p. 127 y ss. [último acceso: 20/09/2015] Disponible en: <http://www.justiciacotidiana.mx/work/models/JusticiaCotidiana/ Resource/101/1/images/Documento_JusticiaCotidiana_VoBo_270415.pdf>

30 En el caso de México, los medios alternativos de solución de controversias han recibido consagración constitucional. El artículo 17, cuarto párrafo de la Constitución Política de los Estados Unidos Mexicanos dispone: "Las leyes preverán mecanismos alternativos de solución de controversias". El artículo 18, sexto párrafo del mismo cuerpo normativo alude a las "formas alternativas de justicia" en materia penal. 
controversias que tuvieran poca o ninguna conexión con ese país y que, por consiguiente, no traerían ningún beneficio como contrapartida al gasto efectuado.

En algunos países, la tendencia a la restricción de la jurisdicción estatal para resolver controversias derivadas de relaciones privadas con elementos de extranjería se hace patente a nivel normativo; en otros, se la advierte en la jurisprudencia. En efecto, tal limitación se refleja claramente en la introducción en los ordenamientos jurídicos estatales de normas que enlistan los supuestos en los cuales los jueces del Estado del que se trate pueden declararse competentes ${ }^{31}$ o que establecen la obligación de interpretar de manera restrictiva los supuestos de jurisdicción exclusiva. Esto significa que las controversias que los jueces nacionales están facultados a resolver deben tener ciertos vínculos -más o menos fuertes- con el Estado que ellos representan y que, fuera de las hipótesis contempladas, esos jueces no pueden ejercer jurisdicción. La vinculación entre una controversia y un foro determinado se lleva a cabo mediante puntos de conexión, que son los mismos que se utilizan para identificar el derecho aplicable al fondo del caso iusprivatista internacional $^{32}$. No obstante, aquí la finalidad del establecimiento de la proximidad se limita a conferir competencia internacional, sin que esto implique que el derecho aplicable a la sustancia del litigio deba necesariamente ser la lex fori ${ }^{33}$.

A modo de ejemplo de normas de los tipos referidos en países del continente americano, se hará alusión a normas vigentes en Panamá y también a una norma interesante que aún no ha sido aprobada por el Poder Legislativo uruguayo. En el ordenamiento jurídico panameño, la competencia del juez de ese país la determina a nivel de fuentes internas el nuevo Código de Derecho Internacional Privado ${ }^{34}$ "o, en su defecto, el Código Judicial o las leyes especiales en función de la materia o naturaleza de la causa jurídica internacional" (artículo 12, $2^{\circ}$ párrafo, Código de DIPr.). El artículo 13 del Código de DIPr. de Panamá contiene una lista de supuestos en los cuales los tribunales

31 FERNÁNDEZ ARROYO. Op. cit., p. 286.

32 AUDIT, Bernard. "Le droit international privé en quête d'universalité". Recueil des cours de l'Académie de Droit International. 2003, t. 305, p. 374. Por ejemplo: domicilio, residencia habitual o nacionalidad de la persona, lugar de localización o de registro de un bien, lugar de comisión de un acto ilícito, lugar de celebración o de cumplimiento de un contrato, autonomía de la voluntad de las partes.

33 Ibíd., p. 375. De todas formas, hay países que en algunos supuestos utilizan el criterio del paralelismo entre jurisdicción y derecho aplicable -como sucede en Venezuela, cuyas normas lo consagran para casos de familia y sucesiones-, en virtud del cual el punto de conexión de la norma de conflicto actúa asimismo como criterio atributivo de jurisdicción. HernándezBretón, Eugenio, Op. cit., p. 226.

34 En adelante, "Código de DIPr.". Este cuerpo normativo fue aprobado el 8 de mayo de 2014 mediante Ley No 7 de la Asamblea Nacional, Gaceta Oficial Digital, No 27530, 08.05.2014, año CX, [último acceso: 20.09.2015]. Disponible en: <https://www.gacetaoficial.gob.pa/ pdfTemp/27530/GacetaNo_27530_20140508.pdf> 
panameños son competentes, que incluye: cuando los bienes o activos del demandado estén situados en la República; en materia de obligación extracontractual, cuando el daño haya tenido lugar allí, salvo pacto en contrario; en cuanto a las acciones personales, cuando el demandado esté domiciliado en Panamá; para demandas derivadas de una relación contractual, cuando los efectos o consecuencia del contrato tengan lugar en territorio panameño o, tratándose de contratos solemnes, cuando éstos sean suscriptos en la República.

Por su parte, el artículo 60 del Proyecto de Ley General de Derecho Internacional Privado de Uruguay ${ }^{35}$ versa sobre la jurisdicción exclusiva de los tribunales de la República y establece expresamente que la misma "tiene carácter excepcional, debe interpretarse restrictivamente, y carece de fuero de atracción sobre otras cuestiones que puedan plantearse respecto del mismo asunto". Adicionalmente, enuncia "a modo de ejemplo" algunas materias consideradas de jurisdicción exclusiva de los tribunales de la República: "derechos reales sobre bienes situados en ella, sistemas registrales organizados por ésta, régimen de protección de la propiedad intelectual e industrial en su territorio, y arrendamientos de bienes inmuebles situados en su territorio si fuere de aplicación el régimen estatutario".

En cuanto a la jurisprudencia en la cual se manifiesta la tendencia a la limitación de la competencia estatal para casos derivados de relaciones privadas internacionales, se mencionará como ejemplo la de los Estados Unidos acerca de dos cuestiones específicas: el principio de proximidad y el forum non conveniens. En 2011, la Suprema Corte de ese país resolvió, en materia de responsabilidad por productos defectuosos ${ }^{36}$, que a pesar de la existencia de ciertos vínculos con territorio estadounidense, sus tribunales no eran competentes. En otros términos, se consideró que las conexiones existentes ${ }^{37}$ no eran lo suficientemente fuertes como para justificar el ejercicio de jurisdicción personal por parte de los tribunales de los Estados Unidos con respecto a fabricantes extranjeros de productos que resultaron ser defectuosos y provocaron daños físicos a distintas personas. Asimismo, en la jurisprudencia de este país del norte

\footnotetext{
35 Última versión oficial, del 11 de septiembre de 2013, disponible en el sitio de internet de la Presidencia de la República Oriental del Uruguay. Disponible en: $<$ http://archivo.presidencia. gub.uy/sci/proyectos/2013/09/mrree_3044.pdf> [último acceso: 20/09/2015]. El proyecto todavía es objeto de discusión en el Poder Legislativo.

36 Casos J. McIntyre Machinery, Ltd. v. Nicastro, 27 de junio de 2011, 131 S. Ct. 2780, http:// www.supremecourt.gov/opinions/10pdf/09-1343.pdf [último acceso: 20/09/2015] y Goodyear Dunlop Tires Operations, S.A. v. Brown et ux., Co-Administrators of the Estate of Brown, et al., 27 de junio de 2011, 131 S. Ct. 2846, http://www.supremecourt.gov/opinions/10pdf/10-76. pdf [ultimo acceso: 20.09.2015], cit. y comentados por BROGAN, James M. "Personal Jurisdiction after Goodyear and McIntyre One Step Forward; One Step Backward?”. University of Pennsylvania Journal of International Law. 2013, vol 34, p. 811-822, y por HOFFHEIMER, Michael H. "General Personal Jurisdiction After Goodyear Dunlop Tires Operations, S.A. v. Brown”. Kansas Law Review. 2012, vol 60, p. 549 y ss., entre otros.

37 Para mayores datos sobre los hechos de cada uno de los casos, véase las decisiones o los comentarios referidos. Ídem.
} 
del continente americano como en la de otros países de common law, goza de amplia aceptación la doctrina del forum non conveniens, en virtud de la cual un tribunal puede discrecionalmente decidir declinar su competencia en un litigio transnacional si existe en el extranjero un tribunal más adecuado o conveniente para resolver la controversia en cuestión. Uno de los casos recientes y relevantes sobre esta doctrina fue resuelto el 5 de marzo de 2007 por la Suprema Corte estadounidense ${ }^{38}$. En el fallo se determinó que no es necesario que un tribunal federal de distrito establezca su competencia antes de declinarla en un caso internacional fundándose en que no es un foro conveniente si estima que un tribunal extranjero sería más apropiado para resolver el fondo del asunto, cuando así lo justifican "consideraciones de conveniencia, justicia y economía judicial". Lo contrario generaría un costo y comportaría un retraso en la impartición de justicia.

Los distintos casos de limitación de la jurisdicción del Estado considerados en este apartado son susceptibles de afectar el acceso a la justicia de los particulares que se ven envueltos en controversias internacionales. Es por ello que, a continuación, se explorará cómo es posible utilizar algunas herramientas de derecho internacional privado con el fin de perseguir de un equilibrio entre los intereses en juego.

\section{EN BUSCA DE UN EQUILIBRIO DE INTERESES: HERRAMIENTAS DE DERECHO INTERNACIONAL PRIVADO}

Entre las distintas herramientas de las que dispone el derecho internacional privado en materia de jurisdicción internacional, tres de ellas serán analizadas en esta sección, desde una perspectiva común. Se las examinará como instituciones que, empleadas siguiendo ciertas pautas, pueden contribuir a lograr un equilibrio entre el interés de acceder a la justicia -o de garantizar tal acceso- y el interés de restringir el ámbito de la jurisdicción estatal en casos iusprivatistas internacionales. Las herramientas seleccionadas son los acuerdos de elección de foro, la doctrina del forum non conveniens y el foro de necesidad.

\subsection{Acuerdos de elección de foro}

Una de las herramientas del derecho internacional privado para

\footnotetext{
38 Sinochem International Co. Ltd. v. Malaysia International Shipping Corporation, 5 de marzo de 2007, 549 U.S. 422, <https://www.law.cornell.edu/supct/pdf/06-102P.ZS> [último acceso: 20/09/2015]. Para un comentario del fallo y una propuesta adicional, véase STANTON HILL, J. "Towards Global Convenience, Fairness, and Judicial Economy: An Argument in Support of Conditional Forum Non Convenience Dismissals Before Determining Jurisdiction in United States Federal District Courts". Vanderbilt Journal of Transnational Law. 2008, vol 41, no 4, p. 1177-1210. [último acceso: 20/09/2015]. Disponible en: <http://www.vanderbilt. edu/jotl/manage/wp-content/uploads/Hill_final_7.pdf>
} 
facilitar el acceso de los particulares a la justicia son los acuerdos de prórroga de jurisdicción, acuerdos de elección de foro o cláusulas atributivas de jurisdicción internacional. La admisión de estos pactos -reconociéndoles validez y permitiéndoles desplegar plenamente sus efectos- comporta otorgarle un papel crucial a la autonomía de la voluntad de los particulares en materia jurisdiccional ${ }^{39}$. Cuando ello sucede, la configuración misma de la proximidad entre la controversia iusprivatista internacional y un foro que sea competente para resolverla ya no es delineada exclusivamente por el legislador, sino que en gran medida queda a cargo de las partes. En otros términos, la proximidad se da en virtud de la voluntad de las partes en conflicto. Sin embargo, mientras los sistemas jurídicos más abiertos a la autonomía de la voluntad no exigen ningún vínculo en particular con el foro elegido, en algunos ámbitos todavía se requiere que el foro elegido presente alguna conexión ${ }^{40}$ con el caso o con las partes.

Se entiende que el interés del Estado cuyos tribunales han sido elegidos por las partes, en limitar el número de controversias transfronterizas en las que intervienen sus órganos jurisdiccionales, debe considerarse satisfecho con la formulación de una elección válida. Y con más razón si se trata de una elección exclusiva, ya que las partes han apostado todas sus cartas en pos de la una solución dictada por un tribunal de ese Estado en concreto.

Como es sabido, los acuerdos de prórroga de jurisdicción internacional pueden celebrarse antes del surgimiento de una controversia -cumpliendo cabalmente las funciones de brindar certeza a las partes de la relación jurídica de base y de prevenir la práctica del forum shopping- o una vez que los hechos litigiosos ya se han producido. En el primer supuesto serán expresos y en el segundo podrán ser expresos o incluso tácitos. Asimismo, el efecto positivo de estos pactos es el de investir de jurisdicción al tribunal de un Estado que usualmente, según las normas aplicables, no sería competente; en tanto que el efecto negativo de los mismos es exactamente el inverso: excluir la competencia de cualquier otro tribunal y especialmente del o de los que habría o habrían sido competentes en virtud de las normas aplicables. Por consiguiente, en principio no se estima adecuado que el

\footnotetext{
39 La importancia de la autonomía de la voluntad en las relaciones privadas internacionales se aprecia no sólo en materia de jurisdicción, sino también en la elección del derecho aplicable al fondo de la controversia, facultad ampliamente aceptada en la contratación internacional y que poco a poco va permeando hacia otras áreas de la vida de las personas en tiempos de gran internacionalización. Por ejemplo, en la Unión Europea se permite la elección del foro y también la elección del derecho aplicable a la sucesión por causa de muerte. Artículos 5 y 22 del Reglamento UE No 650/2012 del Parlamento Europeo y del Consejo de 4 de julio de 2012 relativo a la competencia, la ley aplicable, el reconocimiento y la ejecución de las resoluciones, a la aceptación y la ejecución de los documentos públicos en materia de sucesiones mortis causa y a la creación de un certificado sucesorio europeo, <http://eur-lex.europa.eu/LexUriServ/ LexUriServ.do?uri=OJ:L:2012:201:0107:0134:ES:PDF> [último acceso: 20.09.2015].

40 Es propicio recordar aquí el comentario de Fernández Arroyo acerca de la razón para conservar la exigencia de proximidad.
} 
tribunal elegido por las partes decline su competencia fundándose en la doctrina del forum non conveniens, ni que un tribunal distinto del elegido se declare de todas formas competente ${ }^{41}$.

Cabe aclarar que, de manera general, para que los acuerdos de elección de foro en materia internacional sean válidos, es necesario que ambas partes presten su consentimiento libre e informado acerca de la elección de los tribunales de determinado país. La sumisión a un tribunal extranjero puede ser vista como una cláusula abusiva ${ }^{42}$ y ser declarada nula si se la inserta en un contrato de consumo -donde una de las partes es típicamente débil frente a una contraprarte fuerte que impone sus condiciones generales de contratación-.

Mucha agua ha corrido bajo el puente desde el reconocimiento jurisprudencial de los acuerdos de elección de foro por parte de la Suprema Corte de los Estados Unidos en 1972 hasta la actualidad. En el célebre caso The Bremen v. Zapata Off-Shore Co. ${ }^{43}$ la justicia estadounidense se pronunció por permitir que la cláusula de elección de los tribunales ingleses surtiera efectos, dada la necesidad de que el estado norteamericano participara en el comercio internacional. En los hechos no había ninguna conexión territorial con Reino Unido. Pero en algunos ámbitos se requiere la existencia de una "conexión razonable" 44 con el foro elegido. Aunque en derecho comparado generalmente se admite el ejercicio de la autonomía de la voluntad para atribuir jurisdicción a un tribunal extranjero ${ }^{45}$, la implementación de tal aceptación puede y suele

\footnotetext{
41 En este sentido, aunque refiriéndose a los acuerdos exclusivos de elección de foro, el principio 2.4 de los Principios ALI/UNIDROIT del proceso civil transnacional reza: "El ejercicio de la jurisdicción debe generalmente declinarse cuando las partes han acordado previamente atribuir jurisdicción exclusiva a otro tribunal"; http://www.unidroit.org/english/ principles/civilprocedure/ali-unidroitprinciples-spanish.pdf (último acceso: 20.09.2015). Sin embargo, en Inglaterra los tribunales están facultado a ejercer su discreción para desconocer un acuerdo que elija un tribunal extranjero. HARTLEY, Trevor. Choice of Courts. Oxford: Oxford University Press, 2013, \$1.16. FERNÁNDEZ ARROYO. Op. cit.

42 En este sentido, Frédéric X. c. Facebook Inc., Tribunal de Gran Instancia de Paris, 5 de marzo de 2015. Se declaró el carácter abusivo y la consecuente nulidad de la cláusula de elección de los tribunales de Santa Clara, California (Estados Unidos), incluida en las condiciones generales de contratación de Facebook que fueron oportunamente aceptadas por la parte actora. Véase el reporte del caso elaborado por Laura Carballo Piñeiro para Cartas Blogatorias, publicado en el blog el 25 de marzo de 2015, <https://cartasblogatorias.com/2015/03/26/francia-facebook-ylas-clausulas-abusivas-eleccion-de-foro/> [último acceso: 20.09.215].

4312 de junio de 1972, 407 U.S. 1, № 71-322, https://supreme.justia.com/cases/federal/ us/407/1/case.html [última visita: 20.09.2015]. Para un comentario temprano del fallo, véase JUENGER, Friedrich K. "Supreme Court validation of forum selection clauses". Wayne Law Review. 1973, vol 19, p. 49-60.

44 Artículo 1, b) del Protocolo de Buenos Aires sobre jurisdicción internacional en materia contractual, MERCOSUR\CMC\DEC No 1/94, <http://www.mercosur.int/ msweb/Normas/normas_web/Decisiones/ES/CMC_DEC_1994-001_ES_Protocolo\%20 JurisdicInternaContractual.PDF $>$ [último acceso: 20.09.2015].

$45 \mathrm{El}$ principio 2.1.1 de los Principios ALI/UNIDROIT establece que la jurisdicción sobre las partes puede ser ejercida "Por el consentimiento de las partes para someter su disputa al tribunal". Op. cit.
} 
presentar dificultades ${ }^{46}$.

Entre las normas de fuente interna recientemente aprobadas en el continente americano que expresamente acogen los acuerdos de prórroga de jurisdicción ${ }^{47}$ se encuentra el nuevo Código Civil y Comercial de la República Argentina ${ }^{48}$. El artículo 2605 de este código, denominado "Acuerdo de elección de foro", establece que "En materia patrimonial e internacional, las partes están facultadas para prorrogar jurisdicción en jueces o árbitros fuera de la República, excepto que los jueces argentinos tengan jurisdicción exclusiva o que la prórroga estuviese prohibida por ley"49. Asimismo, el artículo 2606 dispone que la competencia del juez elegido es exclusiva, salvo que las partes expresamente decidan lo contrario. El artículo 2607, por su parte, exige la forma escrita para la prórroga expresa; pero también permite el acuerdo tácito.

Si bien el legislador mexicano no ha reformado en el último tiempo sus normas sobre la materia, hay aquí una novedad en cuanto a las normas de fuente internacional. El $1^{\circ}$ de octubre de 2015, a diez años de su elaboración, habrá entrado en vigor del Convenio de La Haya sobre acuerdos de elección de foro del 30 de junio de $2005^{50}$. México fue el primer país en ratificarlo -el 26 de septiembre de 2007- y durante mucho tiempo el único en haberlo hecho. Esta situación cambió recién el 11 de junio de 2015, con la aprobación por parte de la Unión Europea.

El Convenio se aplica "en situaciones internacionales a los acuerdos exclusivos de elección de foro que se celebren en materia civil y comercial" (artículo 1), más allá de una serie de exclusiones cuidadosamente delineadas por el artículo 2. El acuerdo que designe

46 No es éste el espacio para explayarse al respecto. Sólo se mencionará a modo de ejemplo el caso que dio lugar a la primera opinión consultiva del Tribunal Permanente de Revisión del MERCOSUR (TPR), a propósito del tratamiento que la justicia paraguaya le diera a una cláusula de elección de un tribunal argentino inserta en un contrato internacional. Opinión Consultiva No 1/2007, "Norte S.A. Imp. Exp. c/ Laboratorios Northia Sociedad Anónima, Comercial, Industrial, Financiera, Inmobiliaria y Agropecuaria s/ Indemnización de Daños y Perjuicios y Lucro Cesante", solicitud cursada por la Corte Suprema de Justicia del Paraguay con relación a los autos del Juzgado de Primera Instancia en lo Civil y Comercial del Primer Turno de la jurisdicción de Asunción, <http://www.tprmercosur.org/es/docum/opin/ OpinCon_01_2007_es.pdf> [último acceso: 20/09/2015]. Véase FERNÁNDEZ ARROYO, Diego P. "Forum Selection Clauses within the Mercosouthern Law: the Hard Implementation of an Accepted Rule". Uniform Law Review - Revue de Droit Uniforme. 2008, vol XIII, p. 873-890.

47 Otro caso es el Código de DIPr. de Panamá, supra, nota 34. Véase el artículo 17 de ese código, que permite la prórroga de competencia internacional.

48 Este cuerpo normativo, aprobado por Ley 26.994 y vigente desde el $1^{\circ}$ de agosto de 2015, regula la jurisdicción internacional en el capítulo 2 del título IV, dedicado a las disposiciones de derecho internacional privado. Es posible consultar el texto completo en <http://www. infoleg.gob.ar/infolegInternet/anexos/235000-239999/235975/norma.htm> [último acceso: 20.09.2015].

49 Nótese que la norma transcripta incluye también el acuerdo arbitral a favor de árbitros fuera de la República Argentina.

$50 \mathrm{El}$ texto completo y el estado actual de las firmas y ratificaciones pueden ser consultados en el sitio de Internet de la Conferencia de La Haya de Derecho Internacional Privado: <http:// www.hcch.net/index_es.php?act=conventions.text\&cid=98> [último acceso: 20.09.2015]. 
los tribunales de un Estado contratante se reputará exclusivo, salvo disposición expresa en contrario de las partes (artículo 3, b). No se requiere que el foro elegido cubra otra condición que la de pertenecer a un Estado contratante (artículo 3, b). Sin embargo, se ha incluido la posibilidad de que algún Estado declare "que sus tribunales podrán negarse a decidir sobre un litigio al que se aplica un acuerdo exclusivo de elección de foro si, con excepción del lugar de situación del tribunal elegido, no existe vínculo alguno entre ese Estado y las partes o el litigio". Finalmente, las resoluciones que dichos tribunales dicten deben, en principio, ser reconocidas y ejecutadas en los demás Estados contratantes (artículo 8.1).

Los acuerdos de elección de foro voluntariamente pactados en condiciones que no implican el abuso de una parte con respecto a la otra y la aceptación de su existencia y validez por los Estados con los cuales el litigio se vincula, permiten que haya un equilibrio entre los intereses estatales y los de los justiciables.

\subsection{Forum non conveniens}

La doctrina del forum non conveniens es originaria de Escocia y goza de amplia acogida en los países de common law ${ }^{51}$. La mayoría de los autores de los países de derecho civil no es favorable ${ }^{52}$ a esta herramienta del derecho internacional privado. Sin embargo, algunos otros ${ }^{53}$ impulsan un acercamiento entre tradiciones jurídicas que permitiría, bajo ciertas condiciones, incorporar el forum non conveniens a sistemas de la familia romano-germánica.

Pocos son los sistemas de tradición romano-germánica qué regulan y utilizan esta figura ${ }^{54}$. Este es el caso, en nuestro continente, de la provincia canadiense de Quebec, cuyo Código Civil dispone: "A pesar de ser competente para conocer un litigio, una autoridad de

51 AUDIT, B., Op. cit., p. 388. HERNÁNDEZ-BRETÓN. Op. cit., p. 229.

52 AUDIT, B., Ibídem, p. 390.

53 Véase, en general, Ibídem, p. 392-395. Véase también, proponiendo que se adopte el forum non conveniens en México en particular, GABUARDI, Carlos A. "Entre la jurisdicción, la competencia y el forum non conveniens". Boletín Mexicano de Derecho Comparado. 2008, año XLI, n 121 , p. 113-115. [último acceso: 20/09/2015]. Disponible en: <http://www.ejournal. unam.mx/bmd/bolmex121/BMD000012103.pdf>

54 Uno de ellos es el sistema japonés. De acuerdo con la nueva legislación en materia de procedimientos civiles, un tribunal japonés puede declinar su competencia internacional si hay circunstancias especiales "en las cuales un juicio y una sentencia de un tribunal de Japón afectaría la equidad entre las partes o la realización de un juicio adecuado y rápido, tomando en consideración la naturaleza del caso, el grado de la carga de defenderse para el demandado, la ubicación de la prueba y cualquier otra circunstancia" (artículo 3-9 de la Ley de reforma parcial del Código de Procedimientos Civiles y de la Ley de medidas provisionales). YOKOMIZO, Dai. "The New Act on International Jurisdiction in Japan: Significance and Remaining Problems". Zeitschrift für Japanisches Recht/ Journal of Japanese Law. 2012, $\mathrm{n}^{\circ} 34$, p. 102. [último acceso: 20.09.2015]. Disponible en: <http://sydney.edu.au/law/anjel/ documents/2013/ZJapanR_34_11_Yokomizo_Endf2.pdf> 
Quebec puede, excepcionalmente y a petición de parte, declinar esta competencia si estima que las autoridades de otro Estado están mejor posicionadas para resolver el litigio" 55 . La actitud de desconfianza hacia el forum non conveniens explica que muchos ordenamientos jurídicos la ignoren y que otros directamente la rechacen. Entre estos últimos, merece ser destacado el caso de Panamá, donde el Código Judicial contiene una reacción ante la aplicación de esa doctrina por parte de tribunales extranjeros. El artículo 1421-J dispone: "En los procesos de que trata este Capítulo, no son competentes los jueces nacionales si la demanda o la acción que se intente entablar en el país ha sido rechazada o negada previamente por un juez extranjero que aplique el forum non conveniens. En estos casos, los jueces nacionales deberán rechazar o inhibirse del conocimiento de la demanda o acción por razones de orden constitucional o de competencia preventiva”. Esta norma fue aplicada en un caso resuelto por la Sala Civil de la Corte Suprema de Justicia de Panamá ${ }^{56}$. Sin embargo, recientemente, el Pleno de la misma Corte Suprema de Justicia panameña declaró inconstitucional el artículo 1421-J del Código Judicial de dicho país centroamericano, por impedir el acceso a la justicia ${ }^{57}$.

¿En qué consiste exactamente la doctrina o principio del forum non conveniens? Tal como lo afirma la jurisprudencia estadounidense, "simplemente se trata de que un tribunal puede resistirse a que se le imponga jurisdicción cuando la jurisdicción es autorizada por la letra de una ley general" ${ }^{2}$. Por motivos de tipo práctico, el tribunal considera no ser un foro adecuado para ventilar la controversia, mientras que hay otro foro diferente que sí lo es ${ }^{59}$. Llevada al ámbito de las relaciones internacionales entre particulares, esta doctrina faculta a un tribunal cuyas normas procesales le permiten declararse competente, a llevar a cabo una apreciación discrecional de ciertas circunstancias. Esa valoración es suceptible de conducirlo a declinar su competencia en un litigio transfronterizo cuando existe en el extranjero un tribunal más conveniente para resolver el caso.

La sola idea de que el juez tenga un margen de apreciación tan amplio como para renunciar a ejercer su competencia porque, desde su

55 Para acceder al Código Civil de Quebec en su lengua original: <http://www2. publicationsduquebec.gouv.qc.ca/dynamicSearch/telecharge.php?type=2\&file=/CCQ_1991/ CCQ1991.html> [último acceso: 20/09/2015].

56 Sara Grant Tobal et al c. Multidata Systems International Corp. et al, 3 de agosto de 2010, <https://asadip.files.wordpress.com/2010/09/sc-aug-2010-dec.pdf> [último acceso: 20.09.2015].

5731 de marzo de 2015, http://gacetas.procuraduria-admon.gob.pa/27821-B_2015.pdf(último acceso: 20/09/2015).

58 Esta afirmación fue formulada en un caso interno pero interestatal resuelto por la Suprema Corte de los Estados Unidos: Gulf Oil Corp. v. Gilbert, 10 de marzo de 1947, 330 U.S. 501, $<$ https://supreme.justia.com/cases/federal/us/330/501/case.html>

59 Véase GABUARDI. Op. cit., p. 90 y ss. 
propia perspectiva, un foro extranjero sería más adecuado, refleja un interés concreto del Estado. Es la intención de restringir el número de litigios que debe conocer. Este interés que, como se dijo más arriba, es legítimo, en los supuestos en los que se utiliza el forum non conveniens debe estar aderezado de motivos que harían más práctico y eficaz litigar en el foro alterno. Piénsese por ejemplo en el domicilio de la parte actora cuando hay litisconsorcio activo, en el domicilio de los testigos, o en el lugar donde haya que llevar a cabo ciertas diligencias probatorias.

No obstante, el interés de los particulares en acceder a la justicia podría verse afectado por una declinatoria de competencia fundada en la no conveniencia del tribunal ante el cual se entabló la demanda. Semejante decisión generalmente puede considerarse favorable a la parte demandada, tanto si tiene una conexión sustantiva con el foro por ejemplo, está domiciliada allí- como si no la tiene -por ejemplo, es extranjera reside en el extranjero ${ }^{60}$. Sin embargo, podría resultar fatal para la parte actora y su pretensión de fondo, traduciéndose lisa y llanamente en una denegación internacional de justicia. Porque, más allá de cómo se determine el derecho aplicable a la sustancia del caso y de si éste eventualmente conduciría a una condena de mayor o menor monto $^{61}$, es frecuente que quienes demandan en su propio país tengan problemas para ejecutar el fallo en el extranjero ${ }^{62}$. Esto vulnera el principio "ubi jus, ibi remedium" ${ }^{63} y$, por consiguiente, el derecho de acceder a la justicia.

Se entiende que el forum non conveniens como herramienta del derecho internacional privado no es intrínsecamente negativa. Para buscar un equilibrio entre los intereses divergentes, la clave está en la manera de utilizar esta doctrina. Los países que la acogen deberían implementarla con precaución, insistir en la excepcionalidad de las circunstancias y en el carácter "manifiestamente inadecuado" 64 del foro, cuidando no provocar una denegación internacional de justicia. En efecto, "la esencia del forum non conveniens es, o debería ser, que el juez no puede declinar su competencia cuando esto implica una denegación de justicia para el demandante" 65 .

60 Véase FERNÁNDEZ ARROYO. Op. cit., p. 297.

61 Para proteger a la parte actora en Panamá, el Código Judicial contiene una norma que cumple una función subsidiaria con respecto al artículo 1421-J. Ídem. En efecto, el artículo 1421-K del Código Judicial establece: "En litigios internacionales, el tribunal nacional, a pedido de las partes, podrá aplicar en materia de indemnización y de sanciones pecuniarias conexas a tal indemnización, los parámetros y montos relevantes del Derecho extranjero pertinente". 62 WHYTOCK, Christopher A. y Burke Robertson, Cassandra. "Forum Non Conveniens and the Enforcement of Foreign Judgements”. Columbia Law Review. 2011, vol 111, p. 1482.

63 Ídem.

64 Principio 2.5 de los Principios ALI/UNIDROIT: "Se puede declinar la jurisdicción o suspenderse el procedimiento cuando el tribunal sea manifiestamente inadecuado en comparación con otro más apropiado para ejercerla". Op. cit.

65 FERNÁNDEZ ARROYO. Op. cit. 


\subsection{Foro de necesidad}

El foro de necesidad o forum necessitatis tiene un punto en común con el forum non conveniens: le reconoce al juez el ejercicio de cierta discrecionalidad. Si se le permite a un tribunal declinar su competencia de manera discrecional, la contracara necesaria es que pueda declararse competente para asegurar el acceso a la justicia ${ }^{66}$. Como adecuadamente lo señala B. Audit ${ }^{67}$, esa discrecionalidad se manifiesta de manera negativa en la primera hipótesis y positiva en la segunda. En el foro de necesidad, el tribunal decide declararse competente en un caso iusprivatista internacional a pesar de que el caso no se encuadra en los criterios atributivos de jurisdicción de ninguna norma procesal del foro. Lo hace para evitar una denegación de justicia, porque la parte actora no puede encontrar un foro adecuado en otro país ${ }^{68}$.

La figura del foro de necesidad materializa una excepción a la regla general de que "los tribunales deben declararse incompetentes si de su predeterminación legal no se desprende el diseño de su normativa de competencia (...) el tribunal se declara con competencia a pesar de no estar [ésta] predeterminada con el único fin de evitar una denegación de justicia" 69 .

Se advierte en el forum necessitatis una marcada preocupación del tribunal por garantizar el derecho fundamental de acceso a la justicia. El interés de los particulares, sobre todo el de la parte actora, cobra especial relevancia en este tema tan delicado.

De la propia definición, así como del carácter excepcional de este foro, se desprende lógicamente la consecuencia de que un tribunal puede declararse competente para evitar una denegación internacional de justicia a pesar de que no haya en su sistema una norma expresa que lo faculte a actuar de ese modo. En esas circunstancias, fue un clásico en Argentina el caso Vlasov resuelto por la Suprema Corte de Justicia de la Nación en $1960^{70}$. No obstante, es cada vez más frecuente que los diferentes sistemas normativos contemplen de manera expresa el foro de necesidad.

Ya en 1984, la Convención interamericana sobre competencia en la esfera internacional para la eficacia extraterritorial de las sentencias extranjeras -CIDIP III, La Paz ${ }^{71}$ plasmó esta figura en uno de sus

66 REDFIELD, Stephanie. “Searching for Justice: the Use of Forum Necessitatis”. Georgetown Journal of International Law. 2014, vol 45, p. 916.

67 AUDIT, B., Op. cit., p. 387.

68 Ídem.

69 GONZÁLEZ MARTÍN, Nuria y RODRÍGUEZ JIMÉNEZ, Sonia. Derecho Internacional Privado - Parte General. México: Ed. Nostra Ediciones, 2010, p. 101.

70 Cavura de Vlasov, E. c. Vlasov, A. s. Divorcio y separación de bienes, 25 de marzo de 1960, Fallos, 246:87. Disponible en: <http://fallos.diprargentina.com/2007/02/vlasof.html > [último acceso: 20/09/2015].

71 Disponible en: <http://www.oas.org/juridico/spanish/tratados/b-50.html> [último acceso: 
artículos. Lo hizo en los siguientes términos: "Se considerará también satisfecho el requisito de la competencia en la esfera internacional si, a criterio del órgano jurisdiccional del Estado Parte donde deba surtir efectos, el órgano jurisdiccional que pronunció la sentencia asumió competencia para evitar denegación de justicia por no existir órgano jurisdiccional competente" (artículo 2). La formulación convencional resulta general ${ }^{72}$ si se la compara con codificaciones de los últimos años, en las que se puede apreciar "una tendencia a la reducción del ámbito"73 del foro de necesidad, considerándolo excepcional y exigiendo una conexión suficiente entre el caso y el foro ${ }^{74}$.

En la legislación recientemente aprobada y ya vigente en países de América Latina que consagran la figura que nos ocupa, encontramos el Código de DIPr. de Panamá y el Código Civil y Comercial de la Nación Argentina. El artículo 13, 20 párrafo, del código panameño, dispone que "Los tribunales panameños son competentes cuando el tribunal extranjero incurra en denegación de justicia en perjuicio del nacional". Como puede verse, hay una limitación del foro de necesidad a los casos en los que la persona cuyo derecho de acceso a la justicia sería conculcado sea de nacionalidad panameña.

La nueva legislación argentina, por su parte, establece varias condiciones para que un juez argentino se declare competente en virtud del artículo 2602 del Código Civil y Comercial de la Nación. Ese artículo se titula "Foro de necesidad" y prescribe: "Aunque las reglas del presente Código no atribuyan jurisdicción internacional a los jueces argentinos, éstos pueden intervenir, excepcionalmente, con la finalidad de evitar la denegación de justicia, siempre que no sea razonable exigir la iniciación de la demanda en el extranjero y en tanto la situación privada presente contacto suficiente con el país, se garantice el derecho de defensa en juicio y se atienda a la conveniencia de lograr una sentencia eficaz."

El cúmulo de condiciones exigidas por el artículo 2602 del Código Civil y Comercial no hace sino restringir la cantidad de casos en los cuales los tribunales argentinos podrán ejercer jurisdicción internacional. En el fondo, lo que la norma persigue es la búsqueda de un balance entre el interés de los particulares en acceder a la justicia y el del Estado en limitar su propia competencia. Desde esta perspectiva, puede vérsela como un ejemplo positivo. Sin perjuicio de que habrá que esperar un tiempo para ver cómo se da la implementación práctica del nuevo

20.09.2015].

72 También le cabe este adjetivo calificativo a la regulación del foro de necesidad en la normativa mexicana de fuente interna. Artículo 565 del Código Federal de Procedimientos Civiles: "No obstante lo previsto en el artículo anterior, el tribunal nacional reconocerá la competencia asumida por el extranjero si a su juicio éste hubiera asumido dicha competencia para evitar una denegación de justicia, por no existir órgano jurisdiccional competente. El tribunal mexicano podrá asumir competencia en casos análogos."

73 FERNÁNDEZ ARROYO. Op. cit., p. 302.

74 Ídem. 
artículo argentino, todo indica que ésta sería una manera adecuada de buscar el anhelado equilibrio entre los intereses en juego, mediante la utilización del forum necessitatis como herramienta.

\section{CONCLUSIÓN: DE CARA AL FUTURO}

El acceso a la justicia en las relaciones privadas internacionales es un tema que reviste suma importancia en un contexto de globalización como el actual. En él gravitan intereses de las personas involucradas y del Estado cuyos jueces podrían o deberían intervenir para solucionar una controversia concreta. El interés de las personas en ejercer el derecho fundamental de acceso a la justicia, como medio para satisfacer una pretensión sustantiva, converge con el interés del Estado en la medida en la que éste debe garantizar que los justiciables efectivamente accedan a la justicia. Pero a su vez, el Estado está interesado en limitar el ejercicio de su jurisdicción y en este punto puede haber una divergencia con el acceso a la justicia.

Es posible usar al menos tres herramientas del derecho internacional privado para buscar un equilibrio entre el interés de acceder a la justicia -o de garantizar tal acceso- y el de restringir el ámbito de la jurisdicción estatal en casos iusprivatistas internacionales. Las tres deben ser empleadas con suma precaución. En primer lugar, los acuerdos de elección de foro pactados sin que haya abuso de una parte con respecto a la otra deberían ser reconocidos como válidos por los Estados y éstos deberían permitir que desplieguen sus efectos. En segundo lugar, el forum non conveniens debería ser implementado tomando como guía la excepcionalidad de las circunstancias de cada caso y el carácter manifiestamente inadecuado del foro que declina su competencia. En tercer lugar, el foro de necesidad debería ser utilizado sólo excepcionalmente, para evitar una denegación internacional de justicia, exigiendo la presencia de una conexión suficiente entre la controversia y el foro.

Finalmente, es preciso siempre tener en cuenta que para encontrar un justo equilibrio entre el acceso a la justicia en las relaciones privadas internacionales y el interés estatal en poner un límite al número de causas que sus tribunales atienden, mediante el empleo eficaz de estas herramientas y/o de otras, se requiere avanzar en la vía de la armonización normativa, incentivar el actuar coordinado de los Estados y -en la misma línea- reforzar la cooperación internacional.

\section{RESUMEN BIOGRÁFICO}

María Mercedes Albornoz es Profesora investigadora de la División de Estudios Jurídicos del Centro de Investigación y Docencia Económicas, 
CIDE (México). DEA y Doctora en Derecho Internacional Privado, Université de Paris II, Panthéon-Assas (Francia). Abogada egresada de la Universidad Nacional del Litoral (Argentina).

\section{REFERENCIAS BIBLIOGRÁFICAS}

AUDIT, Bernard. "Le droit international privé en quête d'universalité". Recueil des cours de l'Académie de Droit International. 2003, t. 305, p. 374.

BROGAN, James M. "Personal Jurisdiction after Goodyear and McIntyre One Step Forward; One Step Backward?”. University of Pennsylvania Journal of International Law. 2013, vol 34, p. 811-822

CABALLERO JUÁREZ, José Antonio. El debido proceso. Una aproximación desde la jurisprudencia latinoamericana. México: Suprema Corte de Justicia de la Nación, Oficina en México del Alto Comisionado de las Naciones Unidas para los Derechos Humanos, 2014.

CAPELLETTI, Mauro y GARTH, Bryant. El acceso a la justicia. La tendencia en el movimiento mundial para hacer efectivos los derechos. Trad. de Mónica Miranda. México: Fondo de Cultura Económica, 1996.

D’AVOUT, Louis et al. (ed.). Mélanges en l'honneur du Professeur Bernard Audit. Les relations privées internationales. Paris: LGDJ, Lextenso éditions, 2014.

DUE PROCESS OF LAW (DPLF). INSTITUTO DE DEFENSA LEGAL (IDL). Obstáculos para el acceso a la justicia en las Américas, presentado por ante el Comité Jurídico Interamericano, 2009. [acceso: 20/09/2015]. Disponible en: <http://dplf.org/sites/default/files/obstaculos_para_el_ acceso_a_la_justicia_en_las_americas_version_final.pdf $>$

FERNANDEZ ARROYO, Diego P. “Compétence exclusive et compétence exorbitante dans les relations privées internationales". Recueil des cours de l'Académie de Droit International. 2006, t. 323.

FERNÁNDEZ ARROYO, Diego P. "Forum selection clauses within the Mercosouthern law: the Hard Implementation of an Accepted Rule". Uniform Law Review - Revue de Droit Uniforme. 2008, vol XIII, p. 873-890.

FERNANDEZ ARROYO, Diego P. "La tendance à la limitation de la compétence judiciaire à l'épreuve du droit d'accès à la justice". En D'AVOUT, Louis et al. (ed.). Mélanges en l'honneur du Professeur Bernard Audit. Les relations privées internationales. Paris: LGDJ, Lextenso éditions, 2014, p. 299.

FERNÁNDEZ ARROYO, Diego P. “The limits to the parties' free choice 
of jurisdiction - formal and territorial requirements for the efficacy of choice-of-court agreements". En GRIGERA NAÓN, Horacio A. $\mathrm{y}$ AFFAKI, Bachir Georges (eds.). Jurisdictional Choices in Times of Trouble, Dossiers of the ICC Institute of World Business Law. Kluwer Law International, International Chamber of Commerce (ICC), 2015, p. 78.

FERRAJOLI, Luigi. "La desigualdad ante la justicia penal y la garantía de la defensa pública”. En MINISTERIO PÚBLICO DE LA DEFENSA, ASOCIACIÓN INTERAMERICANA DE DEFENSORÍAS PÚBLICAS. Defensa pública: garantía de acceso a la justicia. Buenos Aires: Editorial La Ley, 2008.

GABUARDI, Carlos A. "Entre la jurisdicción, la competencia y el forum non conveniens". Boletín Mexicano de Derecho Comparado. 2008, año XLI, $\mathrm{n}^{\circ} 121$, p. 69-115. Disponible en: <http://www.ejournal.unam.mx/ bmd/bolmex121/BMD000012103.pdf>

GARGARELLA, Roberto. Too far Removed from the People'. Access to justice for the poor: the case of Latin America, 2002. [último acceso: 20/09/2015]. Disponible en: <http://www.ucl.ac.uk/dpu-projects/ drivers_urb_change/urb_society/pdf_violence_rights/gargarella_ removed_from_people.pdf $>$

GONZÁLEZ MARTÍN, Nuria y RODRÍGUEZ JIMÉNEZ, Sonia. Derecho internacional privado: parte general. México: Ed. Nostra Ediciones, 2010.

GONZÁLEZ MARTÍN, Nuria. Un acercamiento al acceso a la justicia a través de la mediación como medio alterno de solución de conflictos, 2014, p. 103-139 [último acceso: 20/09/2015]. Disponible en: <http://biblio. juridicas.unam.mx/libros/8/3541/7.pdf>

GONZÁLEZ PÉREZ, Jesús. El derecho a la tutela jurisdiccional. $3^{\text {a }}$ ed. Madrid: Civitas Ediciones, 2001.

GRIGERA NAÓN, Horacio A. y Affaki, Bachir Georges (eds.). Jurisdictional Choices in Times of Trouble, Dossiers of the ICC Institute of World Business Law. Kluwer Law International, International Chamber of Commerce (ICC), 2015, vol 12.

GABUARDI, Carlos A. "Entre la jurisdicción, la competencia y el forum non conveniens". Boletín Mexicano de Derecho Comparado. 2008, año XLI, n ${ }^{\circ} 121$, p. 113-115 [último acceso: 20/09/2015]. Disponible en: <http://www.ejournal.unam.mx/bmd/bolmex121/BMD000012103. pdf $>$

HERNÁNDEZ CRESPO, Mariana. "Securing investment: innovative 
business strategies for conflict management in Latin America". En INGEN-HOUSZ, Arnold (ed.). ADR in Business: Practice and Issues across Countries and Cultures II. Kluwer Law International, 2010.

HOFFHEIMER, Michael H. "General Personal Jurisdiction After Goodyear Dunlop Tires Operations, S.A. v. Brown”. Kansas Law Review. 2012, vol 60, p. 549-610.

JUENGER, Friedrich K. "Supreme Court validation of forum selection clauses”. Wayne Law Review. 1973, vol 19, p. 49-60.

KLEINHEISTERKAMP, Jan. International Commercial Arbitration in Latin America. Nueva York: Oceana Publications, 2005.

Ministerio Público de la Defensa. Asociación Interamericana de Defensorías Públicas. Defensa pública: garantía de acceso a la justicia. Buenos Aires: Editorial La Ley, 2008.

OCHOA MUÑOZ, Javier L. "Algunas consideraciones sobre el acceso internacional a la justicia. Hacia un derecho internacional privado al servicio de la justicia”. En MORENO RODRÍGUEZ, José Antonio y MARQUES, Claudia Lima (ed.). Los servicios en el derecho internacional privado. Jornadas de la ASADIP 2014. Porto Alegre, 30-31 de octubre, Porto Alegre: ASADIP, UFRGS, 2014, p. 251.

ORTIZ AHLF, Loretta, "El derecho de acceso a la justicia”. En BECERRA RAMÍREZ, Manuel et al. (ed.). Obra en homenaje a Rodolfo Cruz Miramontes. México: Instituto de Investigaciones Jurídicas, 2008, t. II, p. 408 [último acceso: 20/09/2015]. Disponible en: <http://biblio.juridicas. unam.mx/libros/6/2547/20.pdf>

PADRÓN INNAMORATO, Mauricio. "Acceso a la justicia, vulnerabilidad y exclusión: aproximación a las relaciones dimensionales subyacentes", Sin derechos. En: Exclusión y discriminación en el México actual. México: Instituto de Investigaciones Jurídicas, 2014, p. 70. [último acceso: 20.09.2015] Disponible en: <http://biblio.juridicas.unam.mx/ libros/8/3541/6.pdf>

REDFIELD, Stephanie. "Searching for Justice: the Use of Forum Necessitatis". Georgetown Journal of International Law. 2014, vol 45, p. 893-928.

STANTON HILL, J. “Towards Global Convenience, Fairness, and Judicial Economy: An Argument in Support of Conditional Forum Non Convenience Dismissals Before Determining Jurisdiction in United States Federal District Courts". Vanderbilt Journal of Transnational Law. 2008, vol 41, no 4, p. 1177-1210 [último acceso: 20.09.2015]. Disponible 
en: <http://www.vanderbilt.edu/jotl/manage/wp-content/uploads/Hill_ final_7.pdf $>$

THOMPSON, José. "Comparación de resultados". En THOMPSON. José (es.). Acceso a la justicia y equidad. Estudio en siete países de América Latina. San José: Banco Interamericano de Desarrollo, Instituto Interamericano de Derechos Humanos, 2000.

WHYTOCK, Christopher A. y BURKE ROBERTSON, Cassandra. "Forum Non Conveniens and the Enforcement of Foreign Judgements". Columbia Law Review. 2011, vol 111, p. 1482.

YOKOMIZO, Dai. “The new act on international jurisdiction in Japan: significance and remaining problems”. Zeitschrift für Japanisches Recht/ Journal of Japanese Law. 2012, n 34, p. 102 [último acceso: 20/09/2015]. Disponible en: <http://sydney.edu.au/law/anjel/documents/2013/ ZJapanR_34_11_Yokomizo_Endf2.pdf> 